\title{
Enhancement of Durability Properties and Drying Shrinkage of Heat-treated Oil Palm Shell Species High-strength Lightweight Concrete
}

Ming Kun Yew1*, Ming Chian Yew ${ }^{1}$, Lip Huat Saw ${ }^{1}$, Siong Kang Lim¹, Jing Hang Beh¹, Tan Ching Ng ${ }^{1}$

${ }^{1}$ Lee Kong Chian Faculty of Engineering \& Science, Universiti Tunku Abdul Rahman, Cheras 43000 Kajang, Malaysia

\begin{abstract}
Aim: In this study, the effects of heat-treated and non-treated oil palm shell (OPS) species (dura and tenera) are investigated on the slump, density and compressive strength of oil palm shell concrete (OPSC). Two different species of OPS coarse aggregates are subjected to heat treatment at 65 and $130{ }^{\circ} \mathrm{C}$ with the duration of $1 \mathrm{~h}$. The results show that the workability of the OPSC increases significantly with an increase in temperature of heat-treated of the tenera OPS aggregates. It is found that the maximum achievable 28-days and 180-days compressive strength is 51 and $54 \mathrm{MPa}$, respectively. Furthermore, rapid chloride penetration tests (RCPT), porosity measurement and water absorption tests were performance to signify the effects of heat treatment on different OPS species lightweight concrete (LWC). The use of heat-treated OPS LWC induced the advantageous of reducing the permeability and capillary porosity as well as water absorption. The results showed that the ideal of heat treatment method has enhanced the performance of drying shrinkage. Hence, the findings of this study are of primary importance as they revealed that the heat treatment on OPS species LWC can be used as a new environmentally friendly method to enhance the durability properties and drying shrinkage of OPS LWC.
\end{abstract}

Keywords: Lightweight concrete; oil palm shells; rapid chloride penetration test; water absorption; drying shrinkage

\section{Introduction}

The trend towards modernization in construction industry has caused to a rapid growth and huge demand for concrete. The vast demand for concrete has resulted in the over-exploitation of natural stone deposit such as granite and gravel. As a result of escalating environments problem, it has severely affected the stability of the construction industry. Thus, causing ecological imbalance and the need to find an alternative solution to replace this conventional aggregate material has become necessary. One such alternative is oil palm shell (OPS), which is a form of agricultural solid waste of oil palm manufacturing process. OPS will become an environmental problem if no effort is made to utilise it. Therefore, the oil palm industry and concrete industry must be prepared to take advantage of this situation and utilize the available oil palm waste materials in the best possible way, to solve disposal problems and create value-added products.

The oil palm is a major tree crop growing in regions where the temperature is hot with coastal rain forest such as Malaysia, Indonesia, and Thailand in Southeast Asia, Nigeria in Africa, Colombia and Ecuador in South America, and Papua New Guinea in Oceania (UNEP, 2011). The species of palm tree Elaeis guineensis Jacq was taken to Malaysia from Eastern Nigeria in 1961. The best known of several types of Elaeis guineensis are: Dura, Tenera and Pisifera. Dura is a homozygous dominant with thick shells while pisifera is a homozygous recessive without shells. A ring of fibres called "mesocarp" surrounds the kernel. Dura and Pisifera are crossed to produce Tenera (Janssens, 1927) hybrid seed. Recently, Yew et al. (2014) found that compressive strength for LWC using dura OPS increases significantly compared to tenera OPS, which was $21.8 \%$. In this study, dura OPS with heat treatment is selected and used as the coarse 
aggregate for producing high strength lightweight concrete.

The utilization of OPS as LWA in the production of lightweight aggregate concrete (LWAC) has been a topic of research since early 1984 in Malaysia by Abdullah (1984). Structural lightweight concrete (SLWC) has been used for many years, it can be said that SLWC or high strength lightweight aggregate concrete (HSLWAC) is similar to normal lightweight concrete (NLC) except their density is lower. The density of SLWC typically ranges between 1400 and $2000 \mathrm{~kg} / \mathrm{m}^{3}$ compared with that of $2400 \mathrm{~kg} / \mathrm{m}^{3}$ for NWC (Shannag, 2011). Typically, high strength lightweight aggregate concrete (HSLWAC) has a compressive strength levels between 34 and 69 MPa. HSLWAC has an air-dry density less than 2000 $\mathrm{kg} / \mathrm{m}^{3}$ and water to cement ratio of less than 0.45 (Hoff, 2002). The density of the dura and tenera shells is within the range of a majority lightweight aggregates and the specific gravity ranges between 1.15 and $1.37 \mathrm{~g} / \mathrm{cm}^{3}$ (Yew et al., 2014). Results have shown that, the 28-day air-dry density and oven-dry density for concrete produced from OPS aggregates are approximately 16 and 20\% lower than that of ordinary concrete, respectively (Yew et al., 2014).

Concretes, typically lightweight concretes have been used in construction and its benefit include reduction in dead loads; savings in foundations and reinforcement; improved thermal properties, improved fire resistance; savings in transporting and handling precast units on site; and reduction in formwork and propping. At present, lightweight aggregate concrete can be produced using a variety of lightweight aggregates. Lightweight aggregates can originate from either natural materials, like volcanic pumice; thermal treatment of natural raw materials like clay, slate or shale; manufactured from industrial by-products, such as fly ash; or processing of industrial by-products, such as slag. These types of commercially available lightweight aggregates are obtained through a very high heat treatment method at 1000-1200 ${ }^{\circ} \mathrm{C}$ and results in high fuel costs (Zhang \& Gjorv, 1991). Therefore, towards achieving sustainable environmental and saving in the overall cost of construction, many plant based waste material resources have been researched as potential to be aggregates in the production of lightweight concrete. In Malaysia, it is estimated that over 4.6 million tonnes of OPS as waste materials is produced annually (Teo et al., 2006). Research has already been conducted in order to utilize and improve the economic value of OPS residue by producing 'OPS hollow blocks' for walls and 'OPS concrete' for footings, lintels and beams to achieve affordable and comfortable houses (Teo et al., 2007).

OPS is an organic in nature, its properties may degrade after a certain period of time by fungal decay and termite attack unless pre-treatment is applied on the aggregates. Yew et al. (2014) reported that heat-treated method can be used as a new eco-friendly alternative compared to chemically impregnated on OPS aggregates (Mannan et al., 2006). Therefore, heat-treated can be used as a means to increase the resistance against fungal decay and insect attack and subsequently improve the properties of raw OPS aggregates and the resulting concrete properties. Recently, OPS HSLWAC with a corresponding 28-day compressive strength of more than $40 \mathrm{MPa}$ and a density of about $2000 \mathrm{~kg} / \mathrm{m}^{3}$ have been successfully produced compared to normal strength LWAC (Shafigh et al., 2011, Islam et al., 2016, Yew et al., 2015). In current research, there have no experimental researches have been performed on improving durability properties and drying shrinkage of OPSC, particularly by incorporating heat-treated and non-treated OPS species (dura and tenera) to achieve high strength lightweight concrete. Therefore, the objective of this paper discussed the durability properties and drying shrinkage performance of heat-treated and non-treated OPSC were investigated by means of drying shrinkage, rapid chloride penetration test (RCPT), porosity measurement, water absorption and drying shrinkage tests.

\section{Materials and Methods}

\subsection{Materials}

\subsubsection{Cement}

The cement used in the mixing was Ordinary Portland Cement (OPC) Type 1 (ASTM, 1990). The cement was manufactured by Tasek Corporation Berhard with a specific gravity of $3.14 \mathrm{~g} / \mathrm{cm}^{3}$. The Blaine's specific surface area for this cement was $3510 \mathrm{~cm}^{2} / \mathrm{g}$. The cement content was kept constant at $545 \mathrm{~kg} / \mathrm{m}^{3}$.

\subsubsection{Water and superplasticizer (SP)}


Potable water with $\mathrm{pH}$ value of 6 was used for both mixing and curing. The water to cement ratio of 0.29 was used for all the mixes. The SP used in this study was polycarboxylic ether (PCE) supplied by BASF, which complies with ASTM: C494/C494M-13. The SP was added in all the mixes at a constant amount of $1.0 \%$ of the cement weight in order to facilitate workability.

\subsubsection{Fine and coarse aggregate}

Local mining sand available from Hanson Quarry Selangor was used as the fine aggregate, having a specific gravity, fineness modulus, water absorption and maximum grain size of 2.68, 2.72, 0.97\% and 4.75 mm, respectively. The fine aggregate was dried in an open air before use and was kept constant at $866 \mathrm{~kg} / \mathrm{m}^{3}$ for all mixes.

In this study, crushed dura and tenera OPS species was used as the coarse aggregate as shown in Fig. 1. The dura and tenera OPS were collected from a local crude palm oil factory. The thickness of the OPS used throughout the research was 2.0 to $5.0 \mathrm{~mm}$. Furthermore, OPS were washed and sieved using a $12.5 \mathrm{~mm}$-sieve. The OPS aggregates that were retained in the sieve were crushed using a stone-crushing machine in the laboratory. The crushed dura OPS aggregates were sieved using a $9.5 \mathrm{~mm}$-sieve to remove dura and tenera OPS aggregates with sizes more than $9.5 \mathrm{~mm}$. For investigation of the size effect of OPS aggregate on compressive strength, crushed OPS aggregate sizes that were below $2.36 \mathrm{~mm}$ were removed and the sizes between 2.36 and $9.5 \mathrm{~mm}$ were used. The benefits of using crushed OPS aggregates in OPSC were reported by Yew et al. (2014). In this study, OPS aggregates were heat-treated at $65^{\circ} \mathrm{C}$ and $130^{\circ} \mathrm{C}$ over a period of $1 \mathrm{~h}$ using a temperature-controlled laboratory oven. The heat-treated OPS will be rapidly cooling down by soaking under the water at $22 \pm 2^{\circ} \mathrm{C}$ as shown in Fig. 2. The OPS aggregates were subsequently air dried in the laboratory to attain an approximately saturated surface dry condition. A comparison between the physical properties of heat-treated and without heat-treated of crushed OPS aggregates is presented in Table 1, while the grading of dura and tenera OPS aggregates is presented in Table 2. The OPS content in all the mixes was kept constant at 365 $\mathrm{kg} / \mathrm{m}^{3}$.
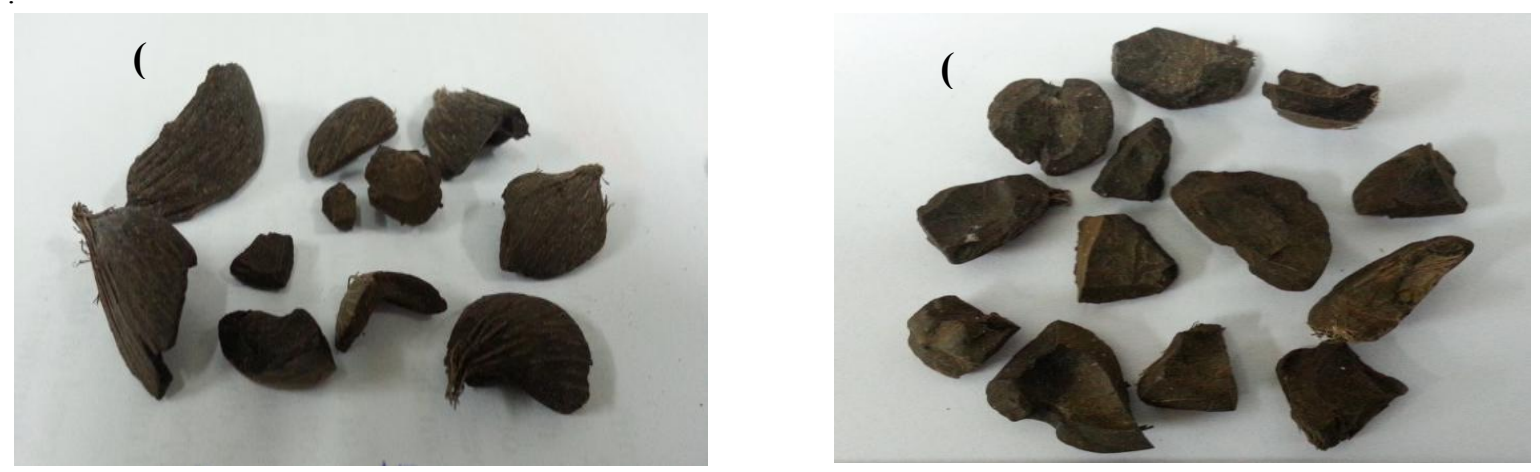

Figure 1. Crushed (a) dura and (b) tenera OPS species between 2.36 and $9.5 \mathrm{~mm}$

\begin{tabular}{|l|l|l|l|l|}
\hline Physical property & dura OPS & dura OPS* & tenera OPS & tenera OPS* \\
\hline Maximum size $(\mathrm{mm})$ & 9.5 & 9.5 & 9.5 & 9.5 \\
\hline Specific gravity (saturated surface dry) & 1.32 & 1.29 & 1.28 & 1.25 \\
\hline Finess modulus & 5.70 & 5.76 & 5.78 & 5.90 \\
\hline Compacted bulk density $\left(\mathrm{kg} / \mathrm{m}^{3}\right)$ & 623 & 617 & 628 & 620 \\
\hline Water absorption $(1$ and $24 \mathrm{~h})(\%)$ & 12.10 and 19.61 & 10.02 and 17.15 & 12.06 and 19.55 & 9.96 and 17.08 \\
\hline Aggregate crushing value $(\%)$ & 2.35 & 2.22 & 2.20 & 2.11 \\
\hline
\end{tabular}

Table 1. Comparison of the physical properties between heat-treated and without heat-treated dura and tenera OPS aggregates 

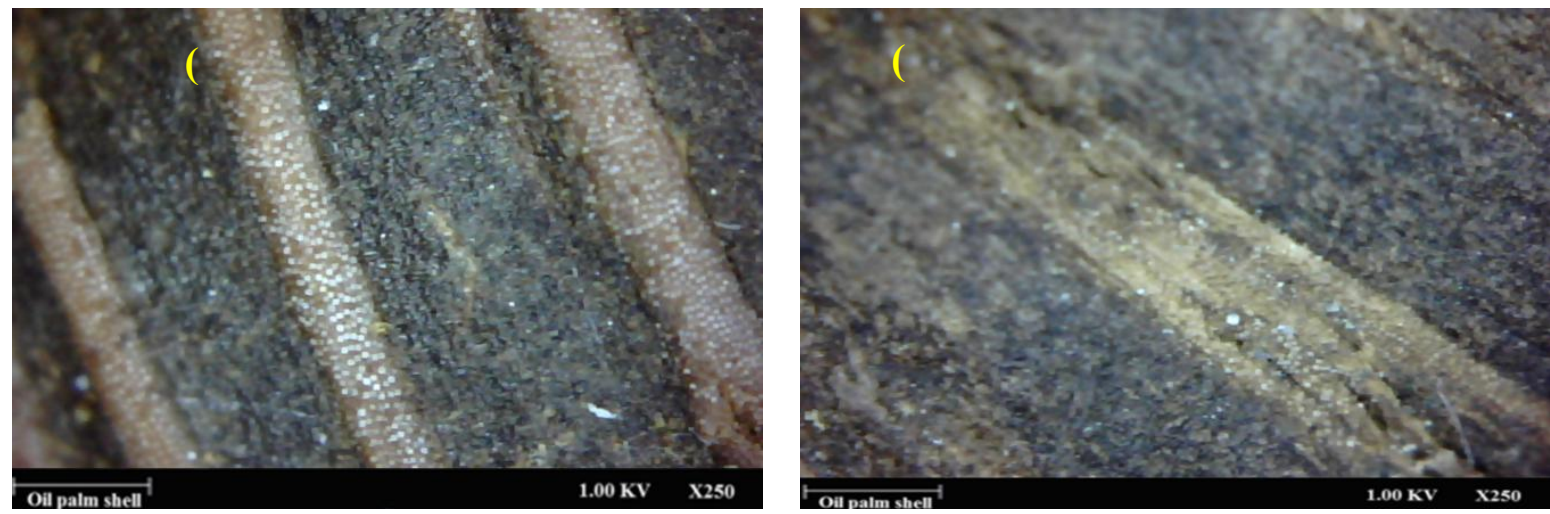

Figure 2. Microscopic images from the surface of OPS aggregates (a) heat treatment and (b) without heat treatment

\begin{tabular}{|l|l|l|}
\hline \multirow{2}{*}{$\begin{array}{l}\text { Sieve } \\
(\mathbf{m m})\end{array}$} & \multicolumn{2}{|l|}{ Cumulative \% by weight passing sieve size } \\
\cline { 2 - 3 } & Crushed tenera OPS $\mathbf{( 9 . 5} \mathbf{~} \mathbf{m})$ & Crushed dura OPS* $\mathbf{9 . 5} \mathbf{~ m m})$ \\
\hline 19.05 & 100 & 100 \\
\hline 12.5 & 100 & 100 \\
\hline 9.5 & 100 & 100 \\
\hline 8 & 93.25 & 93.10 \\
\hline 4.75 & 21.26 & 20.18 \\
\hline 3.35 & 8.27 & 8.20 \\
\hline 2.36 & 4.68 & 4.22 \\
\hline
\end{tabular}

Table 2. Grading of OPS aggregates

\subsection{Mix proportions}

A total of 6 mixes were prepared. The mix proportions of all the concrete mixes used in this study are presented in Table 3. The dosage of water and superplastisizer were kept constant for all mixes.

\begin{tabular}{|c|c|c|c|c|c|c|c|c|c|}
\hline \multirow{2}{*}{ No. } & \multirow{2}{*}{ Mix code } & \multirow{2}{*}{ Cement } & \multirow{2}{*}{ Water } & \multirow{2}{*}{$\begin{array}{l}\text { W/C } \\
\text { ratio }\end{array}$} & \multirow{2}{*}{$\begin{array}{l}\text { San } \\
\text { d }\end{array}$} & \multicolumn{2}{|c|}{ OPS } & \multirow{2}{*}{$\begin{array}{l}\text { Duratio } \\
\text { n (h) }\end{array}$} & \multirow{2}{*}{$\begin{array}{l}\text { Temperatu } \\
\text { re }\left({ }^{\circ} \mathrm{C}\right)\end{array}$} \\
\hline & & & & & & HT & NT & & \\
\hline 1 & T0 & 505 & 146 & 0.29 & 865 & - & 368 & 0 & 0 \\
\hline 2 & D0 & 505 & 146 & 0.29 & 865 & - & 368 & 0 & 0 \\
\hline 3 & $\mathrm{~T} 65 / 1$ & 505 & 146 & 0.29 & 865 & 368 & - & 1 & 65 \\
\hline 4 & D65/1 & 505 & 146 & 0.29 & 865 & 368 & - & 1 & 65 \\
\hline 5 & $\mathrm{~T} 130 / 1$ & 505 & 146 & 0.29 & 865 & 368 & - & 1 & 130 \\
\hline 6 & D130/1 & 505 & 146 & 0.29 & 865 & 368 & - & 1 & 130 \\
\hline
\end{tabular}

Table 3. Mixture proportion $\left(\mathrm{kg} / \mathrm{m}^{3}\right)$

Note: $\mathrm{HT}=$ heat-treated, NT $=$ non-treated

\subsection{Testing methods}

The procedure adopted for mixing the OPSC with heat-treated and non-treated OPS species involves the following steps. Firstly, the sand and OPS were poured into a concrete mixer and dry mixed for $1 \mathrm{~min}$. Secondly, the cement was spread and dry mixed for $1 \mathrm{~min}$. This is followed by the addition of water and superplasticizer with a mixing time of 5 min. Slump test was performed on the mixture prior to sample casting. The concrete specimens were cast in 100-mm cube steel oiled moulds, and a poker vibrator was used to eliminate air bubbles in the mixture. The specimens were demoulded approximately 24 hours after casting and were cured in water at $25 \pm 2{ }^{\circ} \mathrm{C}$ until age of testing. The compression testing machine used was an ELE (Engineering Laboratory Equipment) with a load capacity of $3000 \mathrm{kN}$ running at a pace rate of $3.0 \mathrm{kN} / \mathrm{sec}$, in accordance to BS EN 12390-4:2000. To determine the mechanical properties for 
each mixture, 18 cubes $(100 \times 100 \times 100 \mathrm{~mm})$ are used to determine the compressive strength at $1,7,28$ and, 180 days.

Furthermore, to determine the durability of each mixture, four cylinders (diameter: $100 \mathrm{~mm}$, height: $200 \mathrm{~mm}$ ) were cut into three disc (diameter: $100 \mathrm{~mm}$, height: $50 \mathrm{~mm}$ ). According to the ASTM C-1202 standards, the resistance of the specimens to chloride ion penetration at the age of 7, 28 and 180 days were measured. Total charges passed after $6 \mathrm{~h}$ was obtained from integration of current over the test duration. In this study, porosity measurement was also conducted to measure all the specimens at the age of 28, 90 and 180 days in accordance with RILEM Recommendations (RILEM, 1984). For each mixture, three concrete cubes were cast in order to determine the average value at a particular age. To determine the water absorption of all mixes at the age of 28 days, specimens were dried in the oven at $100 \pm 5{ }^{\circ} \mathrm{C}$ to reach a constant mass and then fully immersed in water with $22 \pm 2{ }^{\circ} \mathrm{C}$ for $72 \mathrm{~h}$. This test was similar to the test conducted by Shafigh et al. (2011) and Teo et al. (2007).

Drying shrinkage measurements were performed according to ASTM: C157-75M-04. The length change of prism $50 \mathrm{~mm} \times 50 \mathrm{~mm} \times 300 \mathrm{~mm}$ was measured by a dial gage extensometer with a $285 \mathrm{~mm}$. Measurements were carried out every two days for the first two weeks, then every week for 1 month and every month up to 365 days.

\section{Results and Discussion}

\subsection{Properties of fresh concrete (Workability)}

In this study, the slump test was carried out to determine the consistency of fresh concrete. The slump value of fresh OPSC and heat-treated OPSC are presented in Fig. 4. The workability of concrete was fixed within a range of 100 $-210 \mathrm{~mm}$ for the slump test. In this study, the quantity of water and SP were kept constant for all mixes in order to access the effects of heat treatment on the workability of OPSC. The aims of heat-treated on different species of OPS is to improve the surface quality. From Fig. 3, it could be seen that the workability of fresh OPSC increases due to an increase of treatment temperature. The T65/1 and D65/1 increase the workability at about $12.9 \%$ and $20.0 \%$ compared to T0 and D0 without heat-treated on OPS. The lowest slump value of D0 may be due to lower surface quality and thicker dura OPS aggregate tend to absorb water compared to other mixes which affects workability. However, it was found that T130/1 and D130/1 mix exhibit a very high workability within a range of $202-210 \mathrm{~mm}$. It can be observed that no segregation in these mixes, which can be attributed to the fact that highest temperature reduces water absorption on thinner tenera OPS compared to dura OPS which also leads to an increase in workability of concrete. Yew et al. (2014) reported that the workability of the concrete can be enhanced by increasing the heat-treated temperature and duration of OPS aggregates.

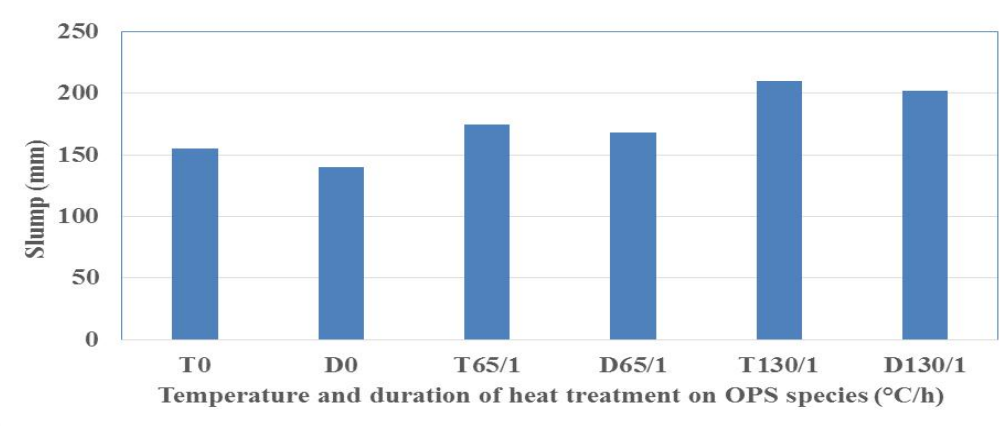

Figure 3; Temperature and duration of heat treatment on OPS species versus slump

\subsection{Density}

Two types of density, namely, demoulded density (DD) and oven-dry density (ODD) were measured for all mixes. Structural lightweight concrete (SLWC) is typically defined as concrete with ODD of not greater than $2000 \mathrm{~kg} / \mathrm{m}^{3}$ (Newman \& Owens, 2003). It can be seen that all OPSC density having an ODD and DD within the range of $1921-$ $1950 \mathrm{~kg} / \mathrm{m}^{3}$ and $1993-2016 \mathrm{~kg} / \mathrm{m}^{3}$ which fulfilled the requirement of structural LWC for all mixes. The DD and 
ODD with the increasing of heat-treated temperature on dura OPS from NT to $65{ }^{\circ} \mathrm{C} / 1 \mathrm{~h}$ and $130{ }^{\circ} \mathrm{C} / 1 \mathrm{~h}(\mathrm{D} 0, \mathrm{D} 65 / 1$ and D130/1) shown the marginal density reduction compared to tenera OPSC (T0, T65/1 and T130/1) at about 0.3\%. This observation is attributed to the weight loss in OPS due to the heat treatment temperature. Other studies observed similar trend by drying wood at high temperature, this phenomenon is due to decrease in hygroscopicity of wood material (Stamn \& Hansen, 1937 and Fengel, 1996).

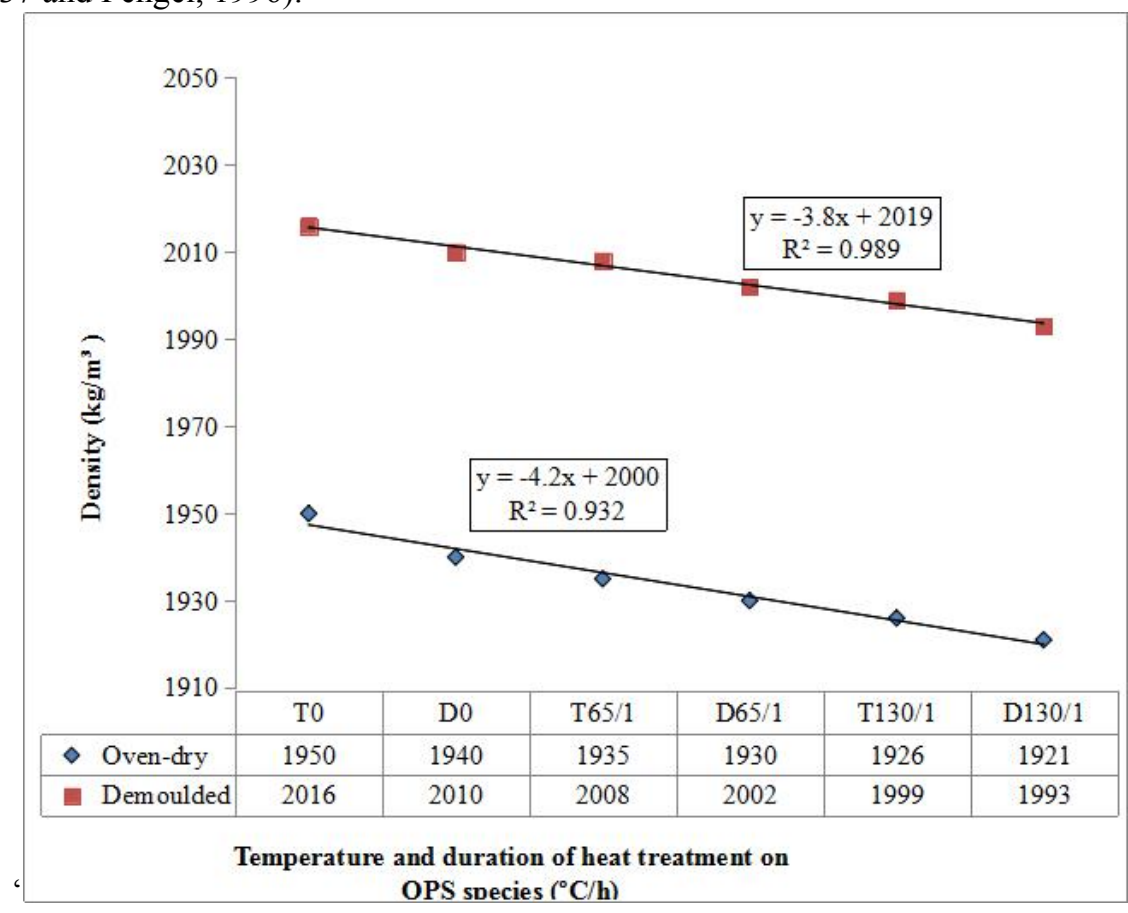

Figure 4; Temperature and duration of heat treatment on OPS species versus density

\subsection{Compressive strength}

\subsubsection{Continuous moist curing}

The results of the compressive strength for all concrete mixes subject to moist curing up to 180 days are presented in Table 4. It could be noted that all the compressive strength of heat-treated and non-treated OPSC increased at all ages, however marginal compressive strength gain at 180-days. Yew et al. (2014) reported that not all type of OPS species aggregates is suitable for production of HSLWC. Therefore, OPS with different species (dura and tenera) have been selected in this study. It also found that, the use of proper heat treatment method on crushed OPS aggregate caused notable surface quality improvement without compromising the strength of the OPSC.

Table 4 shows the compressive strength development for OPSC containing different species of OPS aggregates with heat-treated and non-treated. As can be seen, there is notable difference between D0 and T0 with the increment of $6.8 \%$ compressive strength of D0 compared to T0 at 28 days. The highest compressive strength was achieved for the D65/1 concrete mix, with a value of 50.6 and $53.5 \mathrm{MPa}$ at 28-days and 180-days, respectively. However, the compressive strength decreased significantly with an increase in heat treatment temperature on tenera OPS from T0 to T130/1 at all ages. This may due to the rate of temperature and duration as well as thinner tenera OPS which influence the properties of OPS. On the other hand, a slight increase in compressive strength was observed from D0 to D130/1. Stated differently, the thicker dura OPS aggregate gain in compressive strength by increasing the temperature and duration of heat treatment, relatively to the tenera coarse aggregate with heat-treated and non-treated.

\begin{tabular}{|c|c|c|c|c|}
\hline \multirow{2}{*}{ Mix code } & \multicolumn{4}{|c|}{ Compressive strength (MPa) } \\
\hline & 1d & $7 d$ & 28d & 180d \\
\hline \multirow[t]{2}{*}{ T0 } & 40.86 & 43.45 & 44.08 & 44.38 \\
\hline & $(0.5)$ & $(0.3)$ & $(0.4)$ & $(0.5)$ \\
\hline
\end{tabular}




\begin{tabular}{|c|c|c|c|c|}
\hline \multirow[t]{2}{*}{ D0 } & 41.25 & 45.5 & 46.66 & 47.05 \\
\hline & $(0.3)$ & $(0.1)$ & $(0.3)$ & $(0.2)$ \\
\hline \multirow[t]{2}{*}{$\mathrm{T} 65 / 1$} & 41.12 & 44.25 & 45.18 & 46.62 \\
\hline & $(0.4)$ & $(0.3)$ & $(0.5)$ & $(0.2)$ \\
\hline \multirow[t]{2}{*}{ D65/1 } & 45.62 & 50.31 & 50.60 & 53.50 \\
\hline & $(0.3)$ & $(0.1)$ & $(0.3)$ & $(0.5)$ \\
\hline \multirow[t]{2}{*}{$\mathrm{T} 130 / 1$} & 41.28 & 43.85 & 44.02 & 44.22 \\
\hline & $(0.6)$ & $(0.5)$ & $(0.5)$ & (0.6) \\
\hline \multirow[t]{2}{*}{ D130/1 } & 44.05 & 46.48 & 47.80 & 48.62 \\
\hline & $(0.6)$ & $(0.5)$ & $(0.6)$ & $(0.5)$ \\
\hline
\end{tabular}

Table 4. Development of compressive strength of dura and tenera aggregates OPSC under continuous moist curing

\subsection{Durability Performance}

\subsubsection{Rapid chloride penetration test (RCPT)}

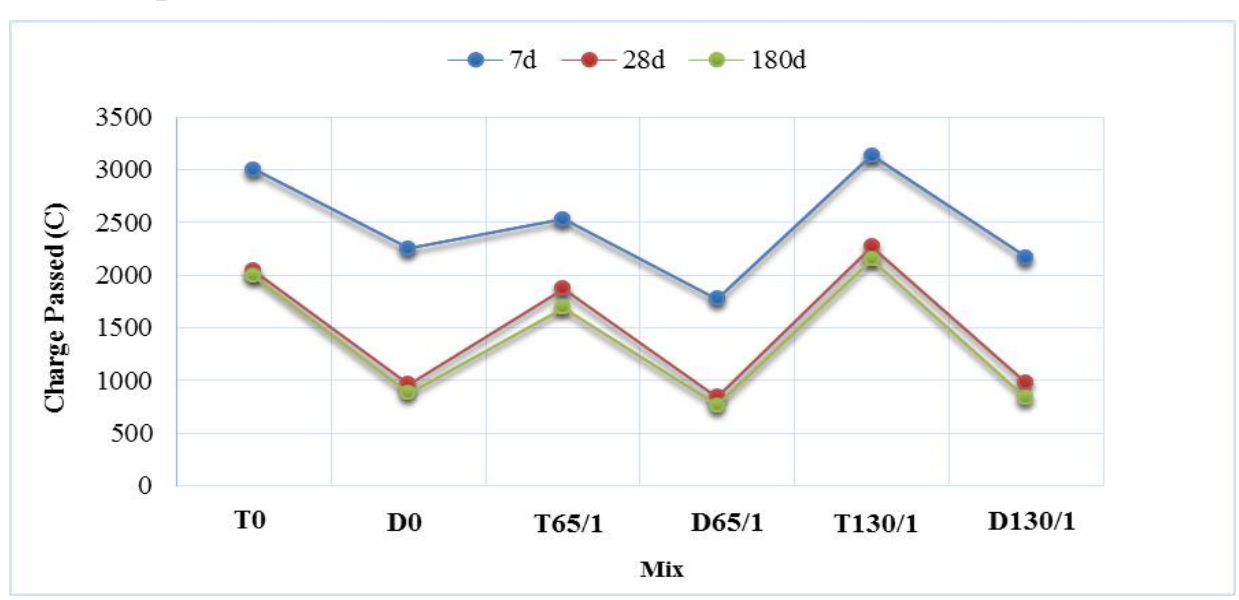

Figure 5; Charge passed versus heat-treated and non-treated on different species aggregate OPSC.

The results of RCPT on 7-day, 28-day and 180-day water cured specimens are illustrated in Fig. 5. It can be seen that, the total transferred charge between the $\mathrm{NaCI}$ and $\mathrm{NaOH}$ cells with electrical potential of $60 \mathrm{~V}$ in $6 \mathrm{~h}$ at all heat-treated aggregate OPSC is significantly lower than that of non-treated aggregate OPSC (T0 and D0). The results show that heat-treated on dura aggregate improved the resistance of concrete to ion penetration. It might be attributed to reduction in inner conductivity of pores and less capillary porosity, which creates the bars of concrete to be more secured from corrosion. In accordance with ASTM C-1202 classification and the RCPT value, all of the heat-treated OPSFRC specimens are classified as "low" and "very low" permeability at 28-days and 180-days, respectively, except for T130/1 achieved above $2000 \mathrm{C}$ considered as "moderator" permeability. From the results, it can be noted that the increase and decrease of charge passed along with the suitable temperature and duration of heat treatment (D65/1) as well as dura aggregates can be related to reduce in porosity which can cause the lower resistance to ion penetration rather than the specimen with higher temperature and duration of heat treatment (T130/1) of tenera species. Thus, it can be deduced that the $(\mathrm{C})$ value measured for the heat-treated on dura aggregates OPSC in this study falls within the range of "low" and "very low" of chloride ion penetrability at 28-days and 180-days. 


\subsubsection{Porosity measurement}

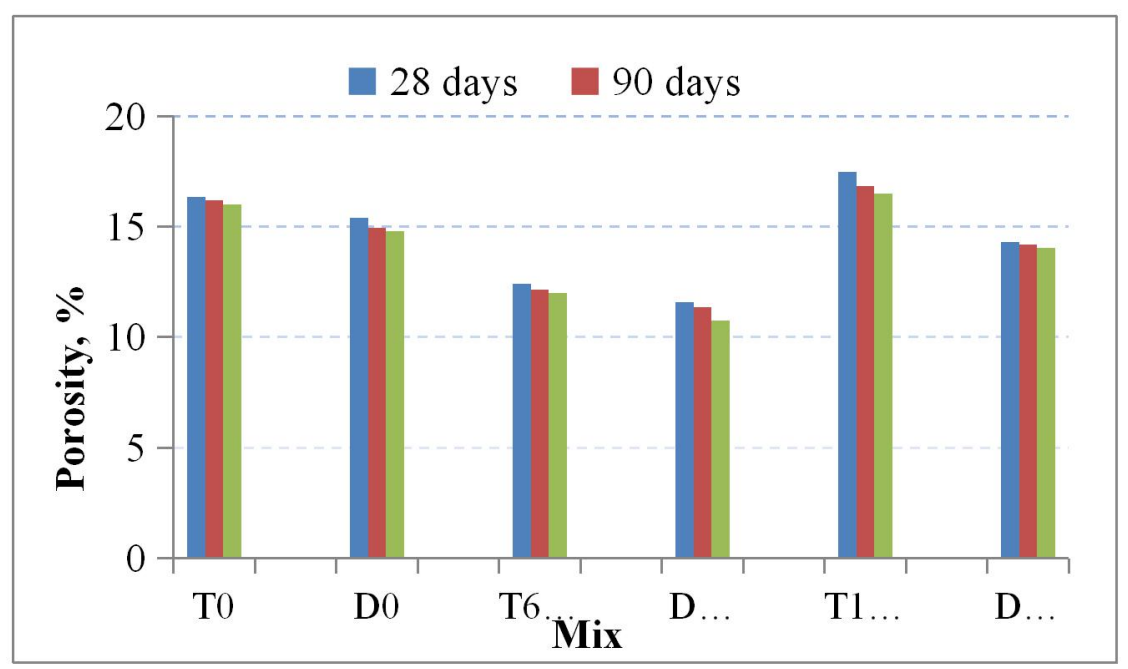

Figure 6; Porosity versus heat-treated and non-treated on different species aggregate OPSC

Porosity is one of the major parameters which influence the strength and durability of concrete. In order to measure the porosity of specimens, porosity measurement test was also performed in addition to RCPT test in this study. It can be related to low porosity cause the low ion chloride penetration rate which resulting of high durability delay the corrosion of specimens. The porosity values measured using the pressure saturation apparatus for OPSC with heat-treated and non-treated OPSC containing of different species aggregate OPSC at 28-days, 90-days and 180-days are presented in Fig. 6. The results indicate that the heat-treated OPSC had a positive effect on porosity as compared to OPSC without heat-treated at all ages investigated. The reduction of porosity measurement for D0 at 28-days, 90-days and 180-days was about $5.9 \%, 7.6 \%$ and $7.7 \%$ as compared to $\mathrm{T} 0$. It can be seen that the porosity reduced with an increase in heat treatment temperature from NT to $65{ }^{\circ} \mathrm{C} / 1 \mathrm{~h}$ and $130{ }^{\circ} \mathrm{C} / 1 \mathrm{~h}$, respectively, except for T130/1 achieved above $16 \%$ at all ages. This may due to the rate of temperature and duration (T130/1) of heat treatment has a negative impact on the properties of tenera OPS. On the other hand, the lowest percentage of porosity measurement shown a positive effect was observed at D65/1. In fact, the reduction in porosity of T65/1 and D130/1 is probably due to the suitable of heat treatment method on OPS species. Therefore, it can be proved that the similar trend of tests on the durability that have performed in this study. Hence, the results approved the validity of RCPT values. It has been reported that the porosity value of normal strength concrete is $17 \%$ for compressive strength less than $50 \mathrm{MPa}$ (Khan, 2007). For self-consolidating high performance concrete, the porosity values range between 6 and 14\% (Safiuddin et al., 2010). Thus, it is worth noting that the porosity value measured for the concrete in this study falls within the range of the results reported.

\subsubsection{Water absorption}

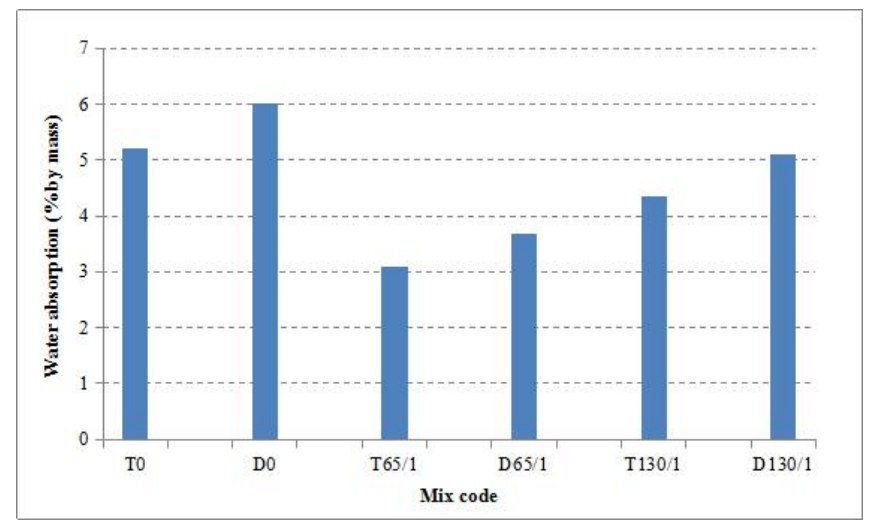

Figure 7. Water absorption versus heat-treated and without heat-treated on different species aggregate OPSC 
Figure 7 shows the water absorption for all mixes. It can be seen that D0 without heat-treated OPS had the highest water absorption value at about $6.02 \%$ while T65/1 with heat-treated dura aggregate OPSC achieved the lowest water absorption of $3.08 \%$. Moreover, it can be observed that the water absorption for tenera heat-treated OPSC is lower compared to dura OPSC without heat-treated. This may be due to the low equilibrium moisture content in OPS when dried wood is subjected to heat treatment (Stamm \& Hansen, 1937), and therefore the heat-treated OPS aggregates tend to reduce the water absorption as compared to OPS without heat-treated. In addition, the inclusion of thinner tenera OPS had a positive effect on water absorption, which can be related to the texture aggregates reduce water absorption. It has been reported that most good concrete have water absorption below $10 \%$ by weight (Neville, 2008). Thus, it can be deduced that the water absorption value measured for the OPSC with and without heat-treated OPSC in this study falls within the range of good concrete. Shafigh et al. (2011) reported that the water absorption for high strength (43 - 48 $\mathrm{MPa}$ ) OPSC is within the range of $3.12-6.20 \%$. Yew et al. (2014) also reported that for high strength $(40-54 \mathrm{MPa})$ OPSC the water absorption fall within the range of $3.04-6.30 \%$. For OPSC with conventional compressive strength $(15-29 \mathrm{MPa})$, the water absorption was in the range between $10.64 \%$ and $11.23 \%$ (Teo et al., 2007).

\subsubsection{Drying shrinkage}

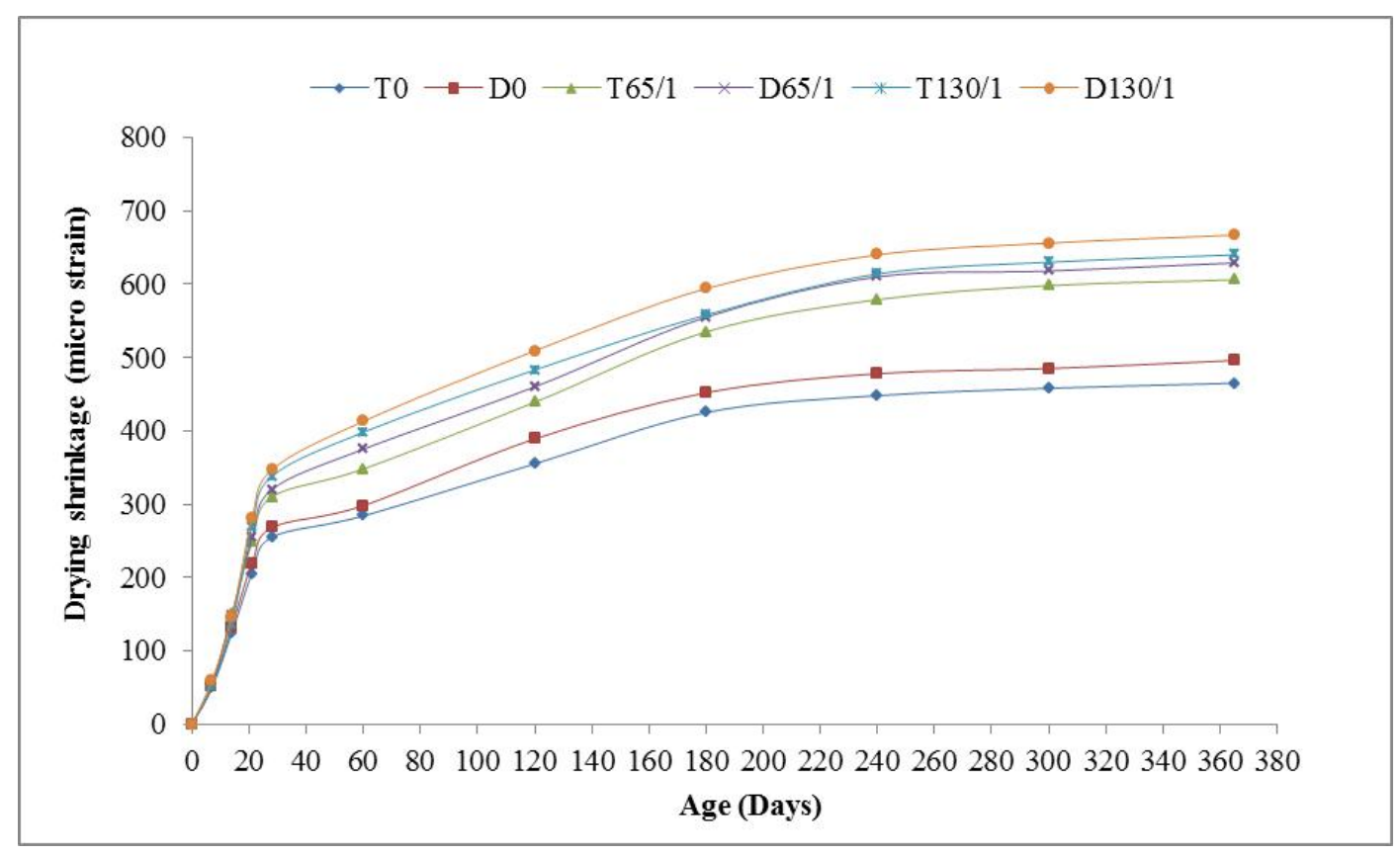

Figure 8. Drying shrinkage of heat-treated and non-treated on different species aggregate OPSC

Figure 8 shows the development of the drying shrinkage of OPSC with heat-treated and non-treated containing different species OPS aggregate. As can be observed that the drying shrinkage curve of heat-treated OPSC is higher than the without heat-treated OPSC at all ages. From the figure, the increasing rate of drying shrinkage of all mixes is typically linear in the first month. However, the magnitude of shrinkage seems to plateau with time. It can be seen that after nearly 240 days of continuous drying, the shrinkage values in T0 and D0 mixes tended to become constant at about 430 micro strain. In contrast, heat-treated OPS species from 65/1 to 130/1 continued to shrink until approximately at 180 days of drying. Shrinkage rate in heat-treated OPSC become very slow after 180 days of continuous drying. The average increment of heat-treated OPSC drying shrinkage value is about $14.5 \%$ compared to OPSC without heat-treated at all ages. Furthermore, the increment of heat-treated OPSC significantly increases the drying shrinkage. Based on the 300 days of continuous drying, the D130/1 had achieved the highest micro strain at about 656 as compared to other mixes at all ages. This phenomenon might be attributed to heat treatment on OPS alter the physical properties of aggregate which resulting in better adhesion between cement paste and OPS. It has been reported that a decrease in hygroscopicity of wood tend to reduced shrinkage and enhancement of dimensional stability may occur when dried wood is subjected to heat treatment (Stamn \& Hansen, 1937 and Rapp, 2001). In addition, an advantage can be obtained 
from including of dura OPS aggregate at 130/1. It could be due to the efficacy of heat-treatment duration on dura species in the arrest of cracking, which results from drying shrinkage (Balaguru \& Slattum, 1995 and Berke \&Dallaore, 1994).

\section{Conclusion}

The effects of incorporating of OPS species at proper duration and heat-treatment on the durability properties and drying shrinkage of high-strength oil palm shell lightweight concrete have been investigated in this study. The following conclusions are drawn based on the experimental results:

1) The workability increases by increasing the duration of heat-treated temperature of OPS aggregates. The slump value for T130/1 and D130/1 mix exhibit a very high workability within a range of $202-210 \mathrm{~mm}$.

2) The compressive strength of heat-treated and non-treated aggregates on OPSC increased at all ages. However, the compressive strength decreased with an increase in heat treatment temperature and duration at T130/1.

3) The results of RCPT test clarify that, by incorporating heat-treated OPS aggregate into OPSC improves the resistance of concrete to ion penetration which may result of concrete to be more secured from corrosion especially at D65/1.

4) Generally high strength concrete has porosity ranging from 12 to $15 \%$. It is recorded that the porosity of heat-treated and non-treated OPSC is within the range of 11 to $17 \%$. Addition of OPS aggregate at $65{ }^{\circ} \mathrm{C} / 1 \mathrm{~h}$ had a positive effect, which can be related to the pore blocking effect of heat-treated OPS.

5) The water absorption of heat-treated and non-treated OPSC value varies from 3.08 to $6.02 \%$ for all mixes, which falls within the range of good concrete.

6) The shrinkage results of OPSC up to 365 days indicated that all heat-treated OPS aggregate exhibited better drying shrinkage than the OPSC without heat-treated.

Author Contributions (as necessary)

All authors have been personally and actively involved in substantive work leading to the manuscript, and will hold themselves jointly and individually responsible for its content.

Acknowledgements (as necessary)

The authors gratefully acknowledge the financial support from University of Malaya and Universiti Tunku Abdul Rahman under the Universiti Tunku Abdul Rahman Research Fund (UTARRF), Project No. IPSR/RMC/UTARRF/2016-C1/Y3. The authors declare that this manuscript no conflict of interest.

\section{References}

1. Abdullah AA. Basic strength properties of lightweight concrete using agricultural wastes as aggregates. In Proceedings of the International Conference on Low-Cost Housing for Developing Countries, Roorkee, India 1984.

2. ASTM C192-90a. Standard test method of making and curing concrete test specimens in the laboratory. Annual Book of ASTM Standards 1990.

3. Balaguru P, Slattum K. Test Methods for durability of polymeric fibers in concrete and UV light exposure. American Concrete Institute, Special Publication 1995; 155: 115-136.

4. Berke NS, Dallaore MP. The effect of low addition rates of polypropylene fibres on plastic shrinkage cracking and mechanical properties of concrete, in: Fiber Reinforced Concrete Developments and Innovations 1994; ACI142(9): $19-42$.

5. Fengel D, On the changes of the wood and its components within the temperature range up to $200{ }^{\circ} \mathrm{C}$-part III: thermally and mechanically caused structural changes in Sprucewood. Holz Roh-u., Werkstoff $1966 ; 24(11)$ : 529-536.

6. Hoff GC. Guide for the useof low-density concrete in civil works projects. US Army Corps of Engineers, Engineering Research and Development Center, ERDC/GSL TR INP 2002-02-7.

7. Islam MMU, Mo KH, Alengaram UJ et al. Durability properties of sustainable concrete containing high volume palm oil waste materials. Journal of Cleaner Production 2016; 137: 167-177.

8. Janssens P. Le palmier a huile au Congo Portugais et dans I'enclave de Cabinda. Descriptions des principales varieties de palmier (Elaeis guineensis) Bulletin Agricole du Congo Belge 1927. 
9. Khan MI. A novel method for measuring porosity. Paper presented at the Proceedings of the 7th Saudi Engineering Conference (SEC7) 2007

10. Mannan MA, Alexander J, Ganapathy C, et al. Quality improvement of oil palm shell (OPS) as coarse aggregate in lightweight concrete. Building and Environment 2006; 41: 1239-1242.

11. Neville AM. Properties of concrete, (CTP-VVP), Kuala Lumpur, Malaysia, 14th edition 2008

12. Newman J, Owens P. Properties of lightweight concrete, Advanced concrete technology set. Oxford: Butterworth-Heinemann 2003

13. Rapp AO. Review on Heat Treatments of Wood, COST ACTION E22 Environmental optimization of wood protection. In: Proceedings of Special Seminar held in Antibes, France 2001

14. RILEM Recommendations. Absorption of water by immersion under vacuum. Materials and Structures 1984; 101: 393-394.

15. Safiuddin M, West JS, Soudki KA. Hardened properties of self-consolidating high performance concrete including rice husk ash. Cement and Concrete Composites , 2010; 32: (9) 708-717.

16. Shannag MJ. Characteristics of lightweight concrete containing mineral admixtures. Construction Building Materials 2011;25(2): 658-662.

17. Shafigh P, Jumaat MZ, Mahmud H et al. Oil palm shell as a lightweight aggregate for production high strength lightweight concrete. Construction Building Materials 2011; 25(4):1848-1853.

18. Shafigh P, Jumaat MZ, Mahmud H, et al. A new method of producing high strength oil palm shell lightweight concrete. Materials \& Design 2011; 32(4): 4839-4843.

19. Shannag MJ. Characteristics of lightweight concrete containing mineral admixtures. Construction Building Materials 2011;25(2): 658-662.

20. Stamm AJ, Hansen LA. Minimizing wood shrinkage and swelling: effect of heating in various gases. Industrial and Engineering Chemistry Fundamentals 1937; 29(7): 831-833.

21. Teo DCL, Mannan MA, Kurian VJ et al. Flexural behaviour of reinforced lightweight OPS concrete beams. In: 9th International conference on concrete engineering and technology, Malaysia 2006; 244-252.

22. Teo DCI, Mannan MA, Kurian VJ, et al. Lightweight concrete made from oil palm shell (OPS): structural bond and durability properties. Building and Environment 2007; 42: 2614-2621.

23. Teo DCL, Mannan MA, Kurian VJ, Ganapathy C. Lightweight concrete made from oil palm shell (OPS): Structural bond and durability properties. Building and Environment 2007;42: 2614-2621.

24. United Nations Environment Programme (UNEP). Oil palm plantation: Threats and opportunities for tropical ecosystems. www.unep.org/GEAS 2012; 22(9)

25. Yew MK, Mahmud H, Ang BC, Yew MC. Effects of oil palm shell coarse aggregate species on high strength lightweight concrete. Scientific World Journal Article ID 2014; 387647: 1-12.

26. Yew MK, Mahmud H, Ang BC. Effects of heat treatment on oil palm shell coarse aggregates for high strength lightweight concrete. Materials \& Design , 2014; 54(0): 702-707.

27. Yew MK, Mahmud H, Ang BC, et al. Effects of low polypropylene twisted bundle fibres on the mechanical properties of high-strength oil palm shell lightweight concrete. Materials and Structures 2015; 1-13.

28. Zhang MH, Gjorv OE. Characteristics of lightweight aggregates for high strength concrete. ACI Materials Journal 1991; 88(2): 150-158. 